\title{
COMPUTER ASSISTED EXERCISES MANAGEMENT ENVIRONMENT FOR CIVIL SECURITY
}

\author{
Irena NIKOLOVA
}

\begin{abstract}
Developing new training models along NATO and EU priorities, conducting computer assisted exercises and applying lessons learned from practical experience contribute to the strengthening the individual and team readiness for crises management. However, no matter how important CAX are for the enhancement of training in the integrated security sector, practically a unified CAX management environment in civil security area is still missing. This environment would form an organizational system comprising concepts, approaches, methodologies, tools and means for effective process implementation and their improvement. A model of unified CAX management environment for concept development, selection of methodology, application of tools, detailed analyses, prognosis, evaluations and scientifically based solutions is presented here. This model is based on the most accepted method for the enhancement of effectiveness, result-oriented management, ensuring transparency and oversight - the application of project management methodology for the entire management of CAX in civil security.
\end{abstract}

Keywords: Computer Assisted eXercises, CAX, management environment, integrated security sector; project management, portfolio management, balanced scorecard.

\section{Introduction}

Up to the beginning of the 1990's 'security' was a synonym of 'defence.' Today, however, in most European countries security is firstly associated to risks like illegal migration, ethnic and religious conflicts, proliferation of weapons of mass destruction and, of course, terrorism and cyber space. ${ }^{1}$ The understanding of security includes as well effective prevention, mitigation and management of the consequences of natural disasters and industrial accidents. That is why security is no longer a purely military concern. Nowadays it is also related to the social-economic development and all elements of society are involved. In accordance, the new demands towards security impose fundamental reforms of the national structures, investment models, systems for management, adoption and mass application of contemporary methods for operations 
research, system analysis and risk management. Without such approach the conclusions and decisions based on them cannot be fully substantiated.

The necessity to perceive the security sector in a comprehensive manner, involving all types of authorities, has been imposed by the complexity of the current security issue. The national security, as well the individual's security has to be ensured within all dimensions - military, political, economic, social and environmental. The more complex understanding of the term "security sector" also reflects such crucial topics of the current political and scientific discourses as good governance, eventually transition or integration in a better way.

Important part of the good governance is the crises management. In this area military and civilian actors need to plan together, operate in complementary ways and support each other. Such a comprehensive approach is an essential part of NATO's transformation in the crisis management domain.

The need to promote a Comprehensive Approach applies not only to operations but more broadly to many NATO efforts, dealing with 21 st century security challenges such as fighting terrorism, improving energy security, preventing proliferation of weapons and dangerous materials, protecting against cyber attacks, and confronting the threat of piracy. NATO's contribution to a Comprehensive Approach is a key feature in the new Strategic Concept. ${ }^{2}$ Main goal in that direction is development of professional forces, flexible enough to execute a broad spectrum of tasks. These forces must be effective, multifunctional, segmented, mobile and professionally trained.

Current technologies bridge the training needs and capabilities improvement. The information technologies provide an optimal way for resolving key issues on national and global level and are appropriate methodologies and tools for enhancing the preparedness and trainings. Applying Modelling and Simulation (M\&S) in staff training is a new form for capabilities development, which is broadly accepted in NATO members. Establishment of centres for modelling and simulations, development of new training models in accordance to NATO standards, execution of computer assisted exercises and usage of lessons learned from practical experience contribute for the improvement of individual and team training.

\section{Computer Assisted Exercise Concept}

The Computer Assisted eXercises (CAX) are one of the valuable tools for enhancing the effectiveness of training and achieving interoperability at lower cost and decreased risks in comparison to field exercises. ${ }^{3} \mathrm{CAX}$ is a tool for testing doctrinal documents implementing the gained experience and lessons learned in past military missions. 
A commonly accepted method for staff and forces training at all levels is usage of M\&S environment. It brings financial benefits and the opportunity to monitor the current state of the military unit's level of training and preparedness and also provides alternative variants for taking actions, aiming to select the most suitable one. So it could be put of planning support environment.

In the security domain real experimentations are very expensive and sometimes, depending on the scenario, are practically impossible. If we measure the added value, the effectiveness of the M\&S tools increases. They provide opportunities to achieve the desired results in shorter time, to analyse multiple alternatives and to select the 'best' one.

At the same time, responding actions during the crises could not be 'programmed.' For that reason very important factor is the decision making of the authorities, which means that conducting CAX with the attendance of responsible bodies from different state institutions is obligatory.

CAX are specifically applicable in situations related to crises management, since the 'recreation' of similar situations in real environment is too complex, economically inefficient and sometimes infeasible. Despite the important role of CAX for enhancing training capabilities in the integrated security sector, a unified CAX management environment is practically missing. Such environment needs to form organizational system of concepts, approaches, methodologies, tools and means for effective realization of processes and its continuous improvement.

Design, development and utilization of unified CAX environment is a new multidiscipline systematic approach for CAX management and provides opportunities for planning, execution and assessment of results of CAX projects in the civil security domain. For the military domain one respective tool used in NATO is JEMM (Joint Exercise Management Module). ${ }^{4}$ Adding a structured framework for project management enables monitoring and control of finances, tasks, resources, information, quality, and risks and guarantees successful accomplishment of projects. The specific benefits are as follows:

- Project implementation in scope, in time and within budget constraints;

- Transparency, distinct distribution of responsibilities and assessment of deliverables and achieved results at each project stage;

- More effective and efficient resource management;

- Storing data and knowledge bases. 


\section{Model of CAX management environment for civil security}

The model of computer assisted exercise management environment for civil security (Figure 1) is based on scientific arguments from the theory of project and portfolio management. ${ }^{5}$ It is approbated according to the criteria for development of low-cost environments for modelling, simulation and trainings in civil security (BEST - Basic (low cost / budget) Environment for Simulation and Training in Emergency Situations was developed under SfP $981149^{6}$ and EU TACOM SEE $2006^{7}$ in the Institute for Parallel Processing at Bulgarian Academy of Science, presented at BAIT-2008 and awarded with special recognition). The environment includes not only hardware, software and infrastructure network, but also human participation and involvement of decision makers from the Integrated Security Sector. The results obtained during simulations enable well-grounded improvements of scenarios and reliable development of future scenarios for defence planning and crises management. ${ }^{8}$

$\mathrm{CAX}$ is a way for resolving defined tasks with known features and time duration and is very similar to the definition of the term 'project.' Each project starts with problem identification, proposal for actions to be taken for resolving it, as well as detailed estimation of resources for its execution. The project is described with its three main features: problem identification, time for resolving and resources needed (financial, human and organizational). In the current case study, the problem occurs in the Integrated Security Sector and is formulated as a task for design, development and execution of CAX in civil security with defined scenarios.

Project initiation could be part of an annual plan for training, necessity for experimentation of new concepts, procedures for reactions in crises management, gained experience in different domains and other available opportunities. It is important, at that stage, to assess the beneficiary's and stakeholders' requirements.

The main idea and understanding of the term 'architecture' is as "the fundamental organisation of a system, describing its components, the connection between them and the environment in which the system functions, as well as the principles managing their design and development." 9 The functioning of security sectors in crisis management exhibit features of complex adaptive systems, ${ }^{10}$ and the architecture of the CAX management environment has to account for such modes of behaviour of the integrated security sector. The architectural approach for CAX management in the security sector aims to achieve work with knowledge of the network and its elements introduced through a common model, description of the architecture of the systems on an operational, system and technical level.

A specific means for the development of the architectural approach is its capacity of solving the problem of planning when certain ready, standardised services, standardised technical and program means, and standardised consumers are available. 


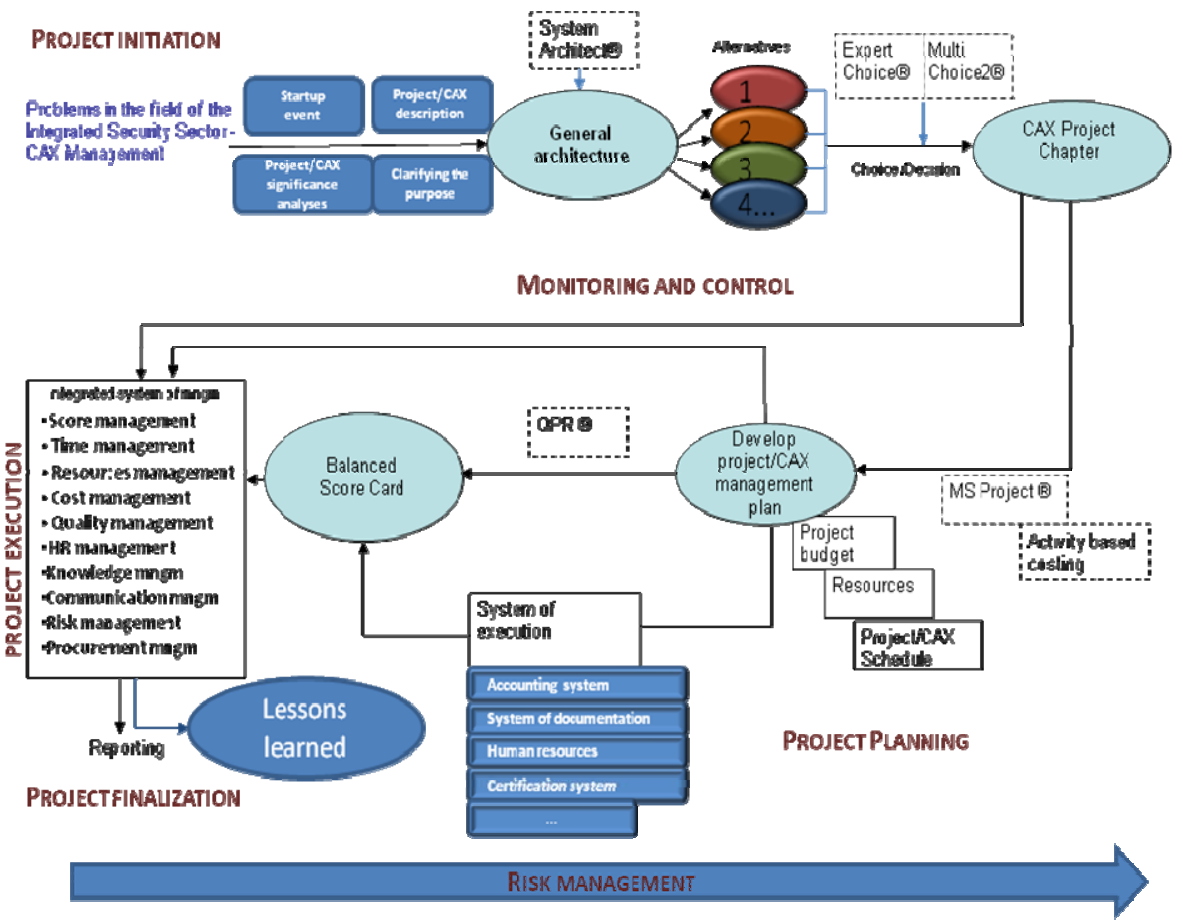

Figure 1: Model for project/CAX management environment.

Then the architectural approach turns into a process of successive answers to questions of the type:

- Who?

- What?

- How much?

- Where?

- When?

- How?

- And possibly why?

The answers to these questions from the operational to the technical level on the basis of certain rules, and existing elements for construction of the system, naturally form the system plan. ${ }^{11}$

A basic advantage of the architectural approach is the possibility to make corrections in the system in the 'rough draft' before it is constructed in practise. This saves im- 
mense efforts and resources and represents a contemporary method for planning and the ability of the system to function according to the requirements of the customer. Architecture is important also because it provides analysis opportunities. It must be described in detail and well documented, thus contributing to a unified understanding of the demands of the system at an early design stage.

The application of the architecture approach is defined, inter alia, in the DoD Architecture Framework, allowing for analysis and design of complex systems, and is supported by different software products. Software products such as System Architect ${ }^{\circledR}$ and Enterprise Architect ${ }^{\circledR}$ provide tools and techniques to system engineers for system analyses. As a result, understandable operational, system and technical views are generated for the designed system.

In the examined model the tool used for the architecture design is System Architect $\AA$. That tool holds out effective opportunities for a comprehensive, non-contradicting description of operational, systematic and technical requirements to all systems that will be used for training and conducting CAX. By using the functionality of System Architect $\AA$ a model for analyses of the resource management processes, problem identification, design and assessment of alternatives in CAX project could be developed.

A number of alternatives are developed by using the architectural model. Every single element of the system can be altered, a new one can be added, the connection between the elements can be altered also, the nature of the elements can be changed and, in this way, a number of alternatives can be generated from one basic architecture. The classical task for evaluation and choice of alternatives consists of three main steps: ${ }^{12}$

- Evaluation;

- Comparison of alternatives;

- Choice.

The choice is made on the basis of three main types of decisions:

- Multi-criteria decisions (goal, criteria, sub criteria);

- Decisions made under the conditions of certain risk;

- Decisions made under high levels of uncertainty.

Often in practise one decision covers all three kinds. In modelling and solving the tasks of the multi-criteria analysis, the following problems occur:

- How to examine a given quantitative criteria; 
- How to compare quantitative and qualitative criteria;

- How to compare more than two quantitative criteria.

The optimality and effectiveness in making decisions in many cases is defined by the quality of the economic, social, organisational and other types of information. The process of making decisions often passes through the following basic phases: ${ }^{13}$

- Defining the decision making problem;

- Selecting criteria and determining restrictions;

- Creating and formulating alternatives;

- Selecting the optimal alternatives from the total generated number;

- Confirming or making decisions;

- Organizing the work for the realisation of the decision, including feedback.

On the basis of the theoretical models, systems for the decision-making are being constructed. They represent interactive computer-based systems designed to help a person who is making a decision when solving weakly formalized or non-formalized tasks (weakly structured or unstructured tasks). There are a number of software products for support to decision making.

The software system 'Expert Choice' is a typical product for selection of alternatives. It is based on the Analytical Hierarchical Process method. The mathematical theory of this method has been developed at the University of Pennsylvania by Thomas Saaty, who is also among the main designers of 'Expert Choice.' The method was created to assist decision making using empirical data as well as the subjective estimation of the person making the decision. The main goals of the system are:

- Creating a hierarchical model for solving a task and an appropriate structuring of the solutions;

- Comparison in pairs of the criteria and sub criteria in relation to their importance for the person making the decision;

- Comparison in pairs of the alternatives in relation to the criteria or their evaluation using functions of usefulness, step functions and different priorities.

Some of the main characteristics of 'Expert Choice' are the following:

- User-friendly interface which facilitates the creation of the hierarchical model of the task and its final solution; 
- Visualisation of the hierarchical model of the task (criteria, sub criteria and alternatives), as well as documenting the received solutions;

- Change of the hierarchical structure of the task and the possibility of visualisation of different parts of that structure;

- Use of a high number of hierarchical levels;

- Easy access to every window of the informational documents which allows the import of video, sound and even the start of other programs;

- Possibility for conversion of a big capacity of data from existing data bases;

- Possibility for export of reports in MS Word and Excel formats.

A web-based version of the 'Expert Choice' system has been created called Expert Choice Group which allows the solving tasks for group decision making. For this purpose every participating individual in a decision making role is given the opportunity to create his or her own hierarchical models of the task being solved and to determine the relative priorities of the criteria.

MultiChoice 2 is the only Bulgarian product for assisting the decision making but it does not fall in quality compared to other products with similar functions and it is easily available. It has a common purpose and can solve all tasks which have been converted to tasks of the multi-criteria analysis. It includes four methods which broadens its usability for different type of tasks and for users with different levels of qualification. Its interface has been fully translated into Bulgarian. It offers the possibility of documenting the process of decision making, as well as the final result, thus documenting the argumentation for the decisions made.

Having made a selection of alternatives, it is necessary to make the next step - project planning. Limited resources and the working to achieve goals to tight deadlines within a fixed budget requires extremely accurate economic evaluation and break down of available resources as well as implementation of effective management tools.

The planning stage of CAX is of the utmost importance. The goals, budget and deadline of the project are set at this stage. Planning is often seen as working out a schedule, resource management, budgeting. A thorough planning goes through the following stages:

- Setting and defining goals;

- Defining activities necessary to bring the project to completion - technical stage;

- Setting tasks, links between them and duration;

- Resource allocation;

- Planning a work schedule; 
- Project, budget and work schedule as part of the 'project plan' given in writing.

One of the crucial factors for the success of the CAX project is working out an accurate and detailed project plan. Following the basic steps in planning the project ensures that there is a clear purpose as well as good coordination and control throughout the project development. The project plan contains the following elements:

- Goal-oriented approach (focus on results);

- Definition of tasks;

- Allocation of resources (i.e. human resources);

- Maximizing results through careful time management.

A well worked-out plan should be used as a tool for:

- Costing;

- Evaluation of results;

- Reporting;

- Management.

In the described environment the tool used for detailed planning is MS Project - one of the most commonly used tools for project planning in many organizations and for different projects.

The complicated dynamics of the modern environment require a complete look over the projects in real time, to make sure that they are aligned and synergetic in approaching the standing aim and strategies. Here comes the role of CAX project portfolio management.

Project portfolio management is a process that enables us to grasp the details of each and every one of our projects - their financial side, benefits and risks. The decisionmaking process as to which project should be launched, stopped or continued ensures that prioritizing and the choice of projects is consistent with the goals of the organization.

The new security environment dictates the implementation of project portfolio management in CAX management, primarily in the process of security sector transformation. The project management of CAX in embedded portfolio facilitates the Management Board in making timely comparisons among the indicators of different planned and ongoing projects. Such management approach shows a clear picture for resource allocation and project prioritization. The application of unified model for CAX management environment provides an opportunity for quick and simple portfolio analysis. The idea is to provide a centralized database and knowledgebase, where information 
gathered from each CAX will be stored, archived, analyzed and updated. Using templates, tables, graphical tools and indicators effectively will provide multi-aspect analysis of CAX on preliminary defined criteria.

The management of several independent CAX outside the portfolio could not provide for a timely and integrated control of their execution. The management staff would not be able to obtain a common picture for the entire progress and understanding how the changes in one of the projects influence other projects.

Costing is one of the most important steps in the process of management and decision making. In the CAX project management model the Activity Based Costing (ABC) method is applied. This method differs from traditional methods in its main focus on the element 'activity.' Activities are considered as fundamental costing objects. The costing process in $\mathrm{ABC}$ is executed in two phases - from resources to activities, and then from activities to the costing objects related to the end results.

The management of project execution involves application of appropriate measurements for successful CAX realization. The complete aggregation of activities during the project execution affords control from the operative level management in all aspects: scope management, time management, resources management, cost management, quality management, HR management, knowledge management, communication management, risk management and procurement management.

Certainty for achieving the targets during project execution is ensured through the controlling processes, through observation and measurement of achieved results and applying, if necessary, corrective actions. Timely results and deliverables are compared on a regular basis with the planned ones. Controlling project processes also includes preventive actions for overcoming possible problems that could occur during the project implementation. Monitoring and control are executed by stakeholders and management staff.

The closing project processes ensure formal finalization and acceptance of the achieved results and deliverables. This phase includes administrative steps and closure of contracts. The project finalization is connected with the evaluation of project outcomes and feedback from the target groups after the exercise. Finally, by the means of lessons learned analyses and comparing the outcomes with the initially planned, conclusion and suggestions for future CAX projects improvements are made. At that project stage complete archiving of documents and results is necessary; reports and other important documents are delivered to the interested sides.

The assessment of CAX projects requires a view in different time horizons: of 'yesterday,' 'today' and 'tomorrow.' Apart of this, the CAX complexity requires a balanced multicriteria evaluation, which could be practically implemented within the 
Balanced Score Card (BSC) methodological system adapted for CAX as shown on Figure 2. This system includes indicators related to all strategically important aspects of the activity (as a minimum: finances, market/clients, internal processes, growth) and determination of cause-effect sequences among all indicators in the system.

The presented BSc assessment offers an explanatory connection of all indicators with the financial results from the CAX activities.

YESTERDAY

TODAY

TOMORROW

\section{Financial}

How to minimize time \& money for implementation of new concept?

- Time for planning/implementation -Budget to run CAX

-Reusability of environment

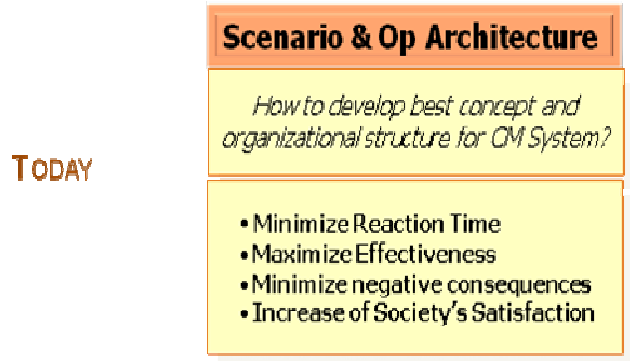

\begin{tabular}{|c|}
\hline Architecture \\
\hline $\begin{array}{c}\text { How to provide best environment for } \\
\text { experimentation \& training? }\end{array}$ \\
\hline \hline - Information flow \\
-Analytical Support \\
- Use of new technologies \\
\hline
\end{tabular}

\begin{tabular}{l} 
CAX team training \& development \\
$\begin{array}{c}\text { How to form and train and develop CAX } \\
\text { prodicts/services for better way achieving other } \\
\text { goals? }\end{array}$ \\
\hline \hline $\begin{array}{l}\text {-Organizational, development, tasking, } \\
\text { training } \\
\text { - Bonus payment \& relating personal }\end{array}$ \\
\hline
\end{tabular}

Figure 2: The Balanced Score Card methodology adapted for CAX. 


\section{Conclusion}

The model of environment for CAX project management in civil security provides a basis for an unified, systematic, multidisciplinary approach for CAX management using scientific proven concepts, best practice methodology for effective planning, execution and evaluation, and tools and methods for CAX design and development for civil security and crises management. Considering the CAX specific features and the best practices, the model has been developed on the conceptual basis for project management. The applied methodology follows the five phases of the project management lifecycle: initiation, planning, execution, control and monitoring and finalization. The selection of adequate tools for operating in the management environment depends on the CAX scale, specificity and resources.

The added value for CAX management in unified environment finds expression in the benefits of implementation of project and portfolio management practices, as well in benefits from its multidisciplinary nature, to the many challenges it raises, passing through the different techniques, models and tools used to solve the multiple problems known. Project management tries to see the CAX as a whole, and systematically challenge the difficulties encountered with new re-thinking processes in order to increase the quality of the CAX management.

In addition, the proposed portfolio project management cycle allows for creation of an excellent basis of information that, with some extension and analysis, may be transformed into knowledge, facilitating consequent analysis of the decisions taken and the scenarios in a specific period of time. This ability can enhance the CAX learning, gathering valuable lessons in order to avoid the repetition of past errors.

So, it is of great importance to develop a flexible and expandable environment for CAX management, which considers concepts, methods, approaches and tools and combines various criteria in the most suitable selection of the project portfolio, involving the full participation of the decision makers and providing the users with a quick feedback.

This model and the respective approach and tools were tested during EU TACOM SEE 2006, working with Monitoring and Information Centre (MIC), operated by the European Commission, and Phoenix 2010 - working with the NATO C3 Agency, the Allied Command Transformation and the NATO Research Technology Organization Modelling and Simulation Group MSG-049.

\section{Notes:}

${ }^{1}$ ESRIF stands for the European Security Research and Innovation Forum, www.esrif.eu (12 Jan. 2011). 
${ }^{2}$ See for example "A 'Comprehensive Approach' to crisis management," NATO A-Z, $<$ www.nato.int/cps/en/natolive/topics_51633.htm> (12 Jan. 2011)

3 Erdal Cayirci and Dusan Marincic, Computer Assisted Exercises and Training. A Reference Guide (Hoboken, NJ: John Wiley, 2009)

${ }^{4}$ See "First JEMM User Conference at NC3A in The Hague," Communications, 7 April 2010, <http://www.nc3a.nato.int/news/Pages/20100801-JEMM-user-conference.aspx> (12 Jan. 2011).

5 J. Rodney Turner, The Handbook of Project-based Management, Second edition (London: McGraw-Hill, 1999); Scott Stewart, Portfolio Management (McGraw-Hill EducationEurope, 2009); Project Management Institute, The Standard for Portfolio Management, Second edition (Global Standard, ANSI/PMI 08-003-2008).

${ }^{6}$ Klaus Niemeyer, Velizar Shalamanov, Todor Tagarev, et al., SfP 981149 Operations Research Support to Force and Operations Planning in the New Security Environment (Sofia: Artgraf, 2008).

7 Project "EU TACOM-SEE 2006 - Terrorist Act Consequences Management," exercise project financed by the European Commission, DG Environment (December 2005 - December 2006), Project Director: Dr. Velizar Shalamanov, IPP-BAS.

8 Velizar Shalamanov, ed., Security Research and Managing Change in the Security Sector (Sofia: George Marshall-Bulgaria, 2008). - in Bulgarian.

9 Mitko Stojkov, Integrated Crisis Management System: Architectural Approach (Sofia: Softtreid, 2006), - in Bulgarian.

${ }^{10}$ See for example Velizar Shalamanov, Stefan Hadjitodorov, Todor Tagarev, Stoyan Avramov, Valentin Stoyanov, Pencho Geneshky, and Nikolay Pavlov, "Civil Security - Architectural Approach in Emergency Management Transformation," Information \& Security: An International Journal 17 (2005): 75-101; Petya Ivanova and Todor Tagarev, "Multiagent Modelling of Critical Infrastructures," Military Journal 113:1 (2006): 97-115. - in Bulgarian.

${ }^{11}$ Computer Assisted Exercises (CAX) for Emergency Management: May 2005 - December 2005, Institute for Parallel Processing - BAS.

${ }^{12}$ Spenser Johnson, "Yes” or "No": The Guide to Better Decisions (New York, NY: HarperCollins, 1992).

${ }^{13}$ Muriel Eddowes and R. Stansfield, Decision Making Techniques (ACCA), Second edition (London: Sweet \& Maxwell, 1992).

IRENA NIKOLOVA has Master's Degree in Security and Defence Economics. She is a Second Grade Research Fellow at the Space Research Institute - Bulgarian Academy of Sciences (BAS) in scientific specialty "Automated systems for information management and processing". She is doing her postgraduate study in "C4I Research and Development" Department at the Institute of Information and Communication technology - BAS. She participated in scientific projects funded by NATO and EU, as well as in projects funded by Ministry of Emergency Situations and Ministry of Defence of the Republic of Bulgaria. Ms. Nikolova has several publications in the field of financial management of scientific projects, economical analysis, implementation of Balanced Scorecard System, optimization, planning and establishment of crisis management systems and computer assisted exercises.

E-mail: itnikolova@abv.bg. 